\title{
Relationship between BMI with percentage body fat and obesity in Singaporean adults - The Yishun Study
}

Kexun Kenneth Chen ${ }^{1 *}$, Shiou-Liang Wee ${ }^{1,2,3^{*}}$ (D) Benedict Wei Jun Pang ${ }^{1}$, Lay Khoon Lau ${ }^{1}$, Khalid Abdul Jabbar ${ }^{1}$, Wei Ting Seah ${ }^{1}$ and Tze Pin $\mathrm{Ng}^{1,4}$

\begin{abstract}
Background: The main aim of this study was to the determine relationship between Body Mass Index (BMI) and percentage body fat (BF\%) in Singaporean adults, derive a prediction model to estimate BF\%, and to report population $\mathrm{BF} \%$. The secondary aim was to determine the prevalence of overweight and obesity based on BF\% threshold and the new risk categories for obesity in Singaporean population.

Methods: This was a population-based study of 542 community-dwelling Singaporeans (21-90 years old, 43.1\% men). Anthropometry and body composition were assessed. Relationship between BMI and BF\% were analysed using multiple regression models. Prevalence of overweight and obesity were estimated using WHO and Singapore Ministry of Health (MOH) Clinical Practice Guidelines for BMI classification, and BF\% cut-off points of 25 and 35\% for men and women respectively.

Results: We derived a prediction model to estimate BF\% based on BMl, age and sex. The current cohort of Singaporeans when compared to Caucasians in the US and Europe as well as a Singapore cohort from 20 years age have higher BF\% when matched for BMI, age, and sex. The overall population-adjusted prevalence of obesity according to $\mathrm{WHO}$ International classification (BMI $\geq 30 \mathrm{~kg} / \mathrm{m}^{2}$ ) was $12.9 \%$ (14.9\% men; $11.0 \%$ women); and $26.6 \%$ (30.7\% men; $22.8 \%$ women) according to the $\mathrm{MOH}$ classification (BMI $\left.\geq 27.5 \mathrm{~kg} / \mathrm{m}^{2}\right)$. However, using the BF\% cut-off (> 25\% for men and $>35 \%$ for women) resulted in very high prevalence of obesity of $82.0 \%$ ( $80.2 \%$ men; $83.8 \%$ women).

Conclusion: There is a large discrepancy between BF\% and BMI measured obesity in Singaporean adults. The results confirmed that Singaporean adults have higher BF\% at lower BMI compared to US and Europe white counterparts; and that BF\% in our population has increased over two decades.
\end{abstract}

Keywords: Obesity, Percentage body fat, BMI, Prevalence

\footnotetext{
* Correspondence: chen.kexunkenneth@gmail.com;

weeshiouliang@gmail.com

${ }^{1}$ Geriatric Education and Research Institute (GERI), 2 Yishun Central 2, Tower

E Level 4 GERI Admin, Singapore 768024, Singapore

Full list of author information is available at the end of the article
}

(c) The Author(s). 2021 Open Access This article is licensed under a Creative Commons Attribution 4.0 International License, which permits use, sharing, adaptation, distribution and reproduction in any medium or format, as long as you give appropriate credit to the original author(s) and the source, provide a link to the Creative Commons licence, and indicate if changes were made. The images or other third party material in this article are included in the article's Creative Commons licence, unless indicated otherwise in a credit line to the material. If material is not included in the article's Creative Commons licence and your intended use is not permitted by statutory regulation or exceeds the permitted use, you will need to obtain permission directly from the copyright holder. To view a copy of this licence, visit http://creativecommons.org/licenses/by/4.0/. The Creative Commons Public Domain Dedication waiver (http://creativecommons.org/publicdomain/zero/1.0/) applies to the data made available in this article, unless otherwise stated in a credit line to the data. 


\section{Introduction}

Obesity is a complex and chronic condition [1], clinically defined as the accumulation of excess body fat to the extent that it may have adverse effects on health [2]. Obesity has long been associated with increased risks of mortality, cardiovascular diseases, diabetes, and cancer, and is associated with significant health and economic burden [3]. BMI has long been used to define obesity in adults. World Health Organization (WHO) recommends an international BMI cut-off point classification for adults: overweight is BMI $25-29.9 \mathrm{~kg} / \mathrm{m}^{2}$ and obesity is BMI $\geq 30 \mathrm{~kg} / \mathrm{m}^{2}$ [4]. In 2016, WHO reported the global prevalence of obesity at $11 \%$ in men and $15 \%$ in women [5]. Despite the relatively stable obesity prevalence in the US (30-34\%) and UK (23-24\%) between 2005 and 2015, the global prevalence has increased due to the rising trend in Asia (including China and India) which comprise a major portion of the world's population [6]. Southeast Asia, with lower initial prevalence of obesity (2-15\%), has also experienced increasing obesity over the last decade, in tandem with globalization, rapid urbanization, and increase in socio-economic status $[7$, 8].

Therefore, it is crucial to determine obesity or threshold of body fat that is associated with increased adverse health risk. Two commonly used methodology used to determine accumulation of body fat are waist circumference and BMI. Waist circumference (WC), measured at midpoint of the last palpable rib and top of iliac crest [9], has good correlation with abdominal adiposity, and strong association with cardiovascular mortality [10]. WC have different cut-off points between Europeans $(102 \mathrm{~cm}$ for men and $88 \mathrm{~cm}$ for women) and Asians (90 $\mathrm{cm}$ for men and $80 \mathrm{~cm}$ for women) due to different body sizes [9]. BMI (body weight divided by height squared) is not a good indicator of body fat, as body weight comprises both fat and fat-free mass. Furthermore, the relationship between $\mathrm{BMI}, \mathrm{BF} \%$, and body fat distribution differ with ethnicity $[11,12]$. Asians are found to have a higher body fat percentage for the same age, gender, and BMI, when compared to European white population, and have higher prevalence of type 2 diabetes (T2DM) and increased cardiovascular risk at lower BMI values compared to European white population [13]. In a crosssectional study of Malaysian women aged 40-59, prevalence of obesity was $72.8 \%$ based on BF\% $(\mathrm{BF} \%>33)$ but only $20.6 \%$ when classified using $B M I \geq 30 \mathrm{~kg} / \mathrm{m}^{2}$ [14]. Therefore, having a common BMI cut-off for obesity is not appropriate, as these cut-off points were derived from studies of the relationship between BMI, morbidity and mortality in the Western populations $[4,15]$.

In 2004, a WHO expert consultation was established to address the appropriate BMI classification for Asian populations [13]. After a series of analyses of BMI, body composition and risk factors of six Asian population data set, consensus was to retain the international BMI cut-off points for Asian populations due to the diverse ethnicity and wide range of cut-off point observed within Asian populations, and further recommended adding cut-off points of $23,27.5,32.5$ and $37.5 \mathrm{~kg} / \mathrm{m}^{2}$ as points for public health actions [13]. Under its current Ministry of Health (MOH) Clinical Practice Guidelines, Singapore adopted the cut-off point of $23 \mathrm{~kg} / \mathrm{m}^{2}$ for overweight, and $27.5 \mathrm{~kg} / \mathrm{m}^{2}$ for obesity [9], as Singaporeans have a higher prevalence of Type 2 diabetes and increased cardiovascular risk factors at BMI below $25 \mathrm{~kg} / \mathrm{m} 2$ [16]. Therefore, measuring obesity based on an individual's $\mathrm{BF} \%$ may be a better indicator of health risks.

Various methods have been developed to measure $\mathrm{BF} \%$, including densitometry, dilution technique and dual energy X-ray absorptiometry (DXA). While WHO has a clear BMI cut-off for defining obesity, there is no clear consensus on the threshold for BF\% for overweight and obesity. Previous studies have suggested that BF\% greater than $25 \%$ for men and $35 \%$ for women is the threshold for diagnosing obesity, which were derived from corresponding BMI of $30 \mathrm{~kg} / \mathrm{m}^{2}$ in Caucasians [17-19]. In a population study, Vietnamese women were reported to have lower BMI, body weight and fat mass than US White women [20]. However, the prevalence of $\mathrm{BF} \%>35$ were similar between the US White women (54\%) and Vietnamese women (53\%) [20].

Singapore is a multiracial and multicultural country, consisting of $74.4 \%$ Chinese, $13.4 \%$ Malays, $9.0 \%$ Indians, and $3.2 \%$ of various other races [21]. In 2013, it was reported that among the three major ethnic group (i.e. Chinese, Malays, and Indians), Chinese had the lowest prevalence of obesity $\left(\mathrm{BMI} \geq 30 \mathrm{~kg} / \mathrm{m}^{2}\right)$ at $5.9 \%$. Indians at $14.0 \%$, and Malays at $20.7 \%$ [22]. In a previous study, Singaporean Chinese was found to have higher cardiovascular risk at low levels of BMI [23]. Relationship between BMI and BF\% in Singaporeans was found to be different from Caucasians, and also among the three major ethnic groups [24]. However, these studies were conducted about 20 years ago. In the recent WHO World Health Statistics, the Singapore population was reported to have similar mortality rate from cardiovascular diseases as Western populations [25]. With the increase in mean BMI in Asians [8], the relationships between BMI and BF\% among Singaporeans have likely changed. As Singapore had adopted the use of BMI 23 $\mathrm{kg} / \mathrm{m}^{2}$ and $27.5 \mathrm{~kg} / \mathrm{m}^{2}$ for overweight and obesity, the prevalence of obesity based on BMI $23 \mathrm{~kg} / \mathrm{m}^{2}$ and 27.5 $\mathrm{kg} / \mathrm{m}^{2}$ should also be studied. The primary aim of this study was to the determine relationship between BMI and $\mathrm{BF} \%$ in the multi-ethnic (Chinese, Malay and Indian) population of Singapore, derive a prediction model to estimate $\mathrm{BF} \%$, and to report population $\mathrm{BF} \%$. The 
secondary aim was to determine the prevalence of overweight and obesity based on BF\% threshold and the new risk categories for obesity in our population.

\section{Methods}

\section{Settings}

Participants were recruited among community-dwelling adults ( $\geq 21$ years) from a large north-eastern residential town of Yishun in Singapore, with residential population of 220,320 ( $49.4 \%$ men), with $12 \cdot 2 \%$ older adults $(\geq 65$ years) [21]. This is similar to the overall Singapore residential population of 4.02 million $(48.9 \%$ men), with $14.4 \%$ older adults ( $\geq 65$ years) [21].

\section{Participants}

Random sampling methodology was employed to obtain a representative sample of approximately 300 male and 300 female participants, filling quotas of $20-40$ participants in each sex- and age-group (10-year age-groups between 21 and 60 years, 5-year age-groups after 60 years). Conventionally, the sample size of 30 or greater per age-group is sufficient for normative measures [26]. Between October 2017 and February 2019, using a twostage random sampling method, $50 \%$ of all housing blocks were randomly selected, and a random $20 \%$ of the units in each block were approached for participant recruitment. Between March and November 2019, 50\% of all housing blocks were randomly selected and all units were approached. Up to three eligible participants were recruited from each housing unit using a door-todoor recruitment method. Non-response units were recontacted a second time at a different time of day on a later date. Older adults above 75 years old were additionally recruited through community sources and from a list of registered participants in four senior activity centres. Exclusion criteria were: individuals with disabilities, injuries, fractures or surgeries that affected function, neuromuscular, neurological and cognitive impairments, or more than five poorly controlled comorbidities. Pregnant women or those planning for pregnancy were also excluded. The estimated overall response rate was $39.0 \%$. Ethics approval was obtained from the National Healthcare Group Domain Specific Review Board (2017/ 00212). All respondents gave informed consent before participation in the study.

\section{Measurements and data collection}

Body weight to the nearest $0.1 \mathrm{~kg}$ and height to the nearest $0.1 \mathrm{~cm}$ were measured using a digital balance and stadiometer (Seca, GmbH \& Co. KG, Hamburg, Germany). Waist and hip circumferences were measured using a non-elastic, flexible measuring tape around the navel and widest part of the hips respectively. These measurements were conducted by trained researchers at the research center. All participants underwent a DXA scan of the whole body (Hologic Discovery Wi, Hologic, Marlborough, MA, USA). The DXA scan was conducted by experienced radiographers. Body composition information - lean mass, fat mass, and bone mineral content, were obtained from the scan.

\section{Overweight and obesity}

Classification of overweight and obesity by BMI were derived using WHO international criteria [4], and Singapore MOH Obesity Clinical Practice Guidelines [9, 13]. Overweight and obesity were defined internationally as having a BMI $25.0-29.9 \mathrm{~kg} / \mathrm{m}^{2}$, and BMI $\geq 30.0 \mathrm{~kg} / \mathrm{m}^{2}$, respectively. Singapore $\mathrm{MOH}$ Clinical Practice Guidelines defined overweight as BMI $23.0-27.4 \mathrm{~kg} / \mathrm{m}^{2}$ and obesity as BMI $\geq 27.5 \mathrm{~kg} / \mathrm{m}^{2}$. The BF\% cut-off points for obesity were set at $25 \%$ for men, and $35 \%$ for women [ 4 , $17,27]$. Waist circumference (WC) for abdominal obesity was defined as above $80 \mathrm{~cm}$ for women, and above $90 \mathrm{~cm}$ for men in Singapore [9].

\section{Statistical analysis}

All statistical analyses were performed using SPSS Statistics version 22.0 (IBM, Armonk, NY, USA). Relationship between $\mathrm{BMI}$ and $\mathrm{BF} \%$ was analysed using forwardbackwward stepwise linear regression models. BF\% was considered the dependent variable; 1/BMI and age were independent variable. Data was analysed separately by sex. In exploratory analysis, the relationship between $\mathrm{BMI}$ and $\mathrm{BF} \%$ was not linear, hence $1 / \mathrm{BMI}$ variable was used to linearise the data and to avoid the need for logarithmic conversion or the inclusion of power [28, 29]. Potential interaction variables were explored in model development and a forward-backward stepwise procedure was utilised for the development of the prediction equation models. Values are presented as mean \pm standard deviation (SD), unless otherwise stated.

\section{Results \\ Subjects}

A total of 542 participants $(43.1 \%$ men) aged 21 years and above were recruited for the study. Due to incomplete data from five participants, data from the remaining 537 participants (81.6\% Chinese, 8.9\% Malay, $6.7 \%$ Indians, and $2.8 \%$ from other races) were analysed. The ethnic distribution was similar to that of Singapore's population [21]. Table 1 shows the demographic characteristics of the participants. As expected, men were taller and heavier, had lower $\mathrm{BF} \%$, higher fat-free mass, lower fat mass, and higher bone mineral content $(p<0 \cdot 005)$. BMI was not significantly different between men and women $(p=0 \cdot 071)$. 
Table 1 Participant Demographic Characteristics

\begin{tabular}{l} 
Variable \\
\hline Number of participants \\
Age (yr) \\
Number of participants by age group \\
$21-29$ \\
$30-39$ \\
$40-49$ \\
$50-59$ \\
$60-64$ \\
$65-69$ \\
$70-74$ \\
$75-79$ \\
$80+$
\end{tabular}

Weight $(\mathrm{kg})$

Height $(\mathrm{cm})$

Waist Circumference $(\mathrm{cm})$

Overall BMI $\left(\mathrm{kg} / \mathrm{m}^{2}\right)$

BMI by age-group

$21-29$
$30-39$
$40-49$
$50-59$
$60-64$
$65-69$
$70-74$
$75-79$
$80+$

Overall Body Fat Percentage (\%)

Body Fat Percentage by age-group

\begin{tabular}{|c|c|c|c|}
\hline $21-29$ & $29 \cdot 6 \pm 8 \cdot 1$ & $37 \cdot 0 \pm 6 \cdot 4$ & \\
\hline $30-39$ & $29.7 \pm 6 \cdot 7$ & $37 \cdot 7 \pm 5 \cdot 7$ & \\
\hline $40-49$ & $31 \cdot 0 \pm 4 \cdot 8$ & $39 \cdot 2 \pm 4 \cdot 7$ & \\
\hline $50-59$ & $28 \cdot 0 \pm 4 \cdot 3$ & $40 \cdot 0 \pm 4 \cdot 5$ & \\
\hline $60-64$ & $29 \cdot 1 \pm 5 \cdot 1$ & $40 \cdot 9 \pm 4 \cdot 9$ & \\
\hline $65-69$ & $30 \cdot 0 \pm 5 \cdot 0$ & $41 \cdot 0 \pm 4 \cdot 1$ & \\
\hline $70-74$ & $30 \cdot 9 \pm 5 \cdot 8$ & $39 \cdot 3 \pm 5 \cdot 0$ & \\
\hline $75-79$ & $30 \cdot 3 \pm 4.9$ & $41 \cdot 2 \pm 5 \cdot 1$ & \\
\hline $80+$ & $31 \cdot 3 \pm 5 \cdot 4$ & $40 \cdot 6 \pm 5 \cdot 5$ & \\
\hline Fat mass (kg) & $21 \cdot 0 \pm 8 \cdot 2$ & $23 \cdot 2 \pm 6 \cdot 6$ & $<0.005$ \\
\hline Fat mass Index (kg/m2) & $7 \cdot 6 \pm 2 \cdot 9$ & $9 \cdot 7 \pm 2 \cdot 7$ & $<0.001$ \\
\hline Fat-free mass $(\mathbf{k g})$ & $45 \cdot 1 \pm 8.9$ & $32 \cdot 6 \pm 5 \cdot 0$ & $<0.001$ \\
\hline Fat-free mass index $(\mathrm{kg} / \mathrm{m} 2)$ & $16 \cdot 2 \pm 2 \cdot 3$ & $13 \cdot 6 \pm 1 \cdot 8$ & $<0.001$ \\
\hline Bone mineral content $(\mathrm{kg})$ & $2.40 \pm 0.43$ & $1.88 \pm 0.36$ & $<0.001$ \\
\hline
\end{tabular}

Values are mean \pm standard deviation, or actual number of participants
Relationship between $\mathrm{BMI}$ and $\mathrm{BF} \%$

For the BF\% prediction equation model, only data from the Chinese ethnic group $(n=438)$ was analyzed, as the ample sizes for Malay, Indian, and other races were too small. The relationship between BMI and BF\% was curvilinear (Fig. 1a). We replaced BMI with 1/BMI as the independent variable to linearize the relationship (Fig. 1b \& c). The regression models with 1/BMI provided higher multiple $R$ and $S E E$ values, compared to logarithmic transformed BMI values, as was reported previously [30]. Table 2 shows the regression coefficients of the stepwise multiple regression. The final prediction equation derived was,

$$
\begin{aligned}
& \text { Men : Percentage Body Fat } \\
& \quad=49.818+0 \cdot 089(\text { Age })-619 \cdot 808(1 / \mathrm{BMI})
\end{aligned}
$$

$$
\begin{aligned}
\text { Women : Percentage Body Fat } \\
=58.159+0 \cdot 051(\text { Age })-516 \\
\\
\cdot 401(1 / \mathrm{BMI})
\end{aligned}
$$

where multiple $R=0.73$, SEE $=3.69 \%$ body fat for men $(p<0.05)$, and multiple $R=0.75$ and $\mathrm{SEE}=3.45 \%$ body fat for women $(p<0.05)$. Based on the estimated parameters of these equations, BF\% values corresponding with BMI for men and women were derived (Table 3). Estimated BF\% of White, Japanese, and Vietnamese were derived from studies that published ethnicity specific equation models [30, 31]. Comparing estimated BF\% from this study and from the 1998 National Heath Survey using equations published [24], men and women in 1998 were found to have lower BF\% across all ages, ethnicity, and BMI categories, except for BMI $35.0 \mathrm{~kg} / \mathrm{m}^{2}$ and above (Supplementary Table).

\section{Prevalence of overweight and obesity}

The prevalence of overweight and obesity are presented in Table 4. According to WHO International BMI classification, the overall population-adjusted prevalence of overweight was $34.4 \%$ (39.1\% men; $29.9 \%$ women), and obesity was $12.9 \%$ ( $14.9 \%$ men; $11.0 \%$ women). Using the $\mathrm{MOH}$ classification, the prevalence of overweight was $41.8 \%$ (44.5\% men; $39.3 \%$ women) and obesity $26.6 \%$ (30.7\% men; $22.8 \%$ women). Using WHO proposed BF\% cut-off, prevalence of obesity increased to $82.0 \%$ overall (80.2\% men; $83.8 \%$ women). Using WC criteria, prevalence of abdominal obesity was $59.1 \%$ (55.7\% men, $62.3 \%$ women).

\section{Discussion}

Percentage body fat

In this study, we established the relationship between BMI and BF\% in Singapore Chinese adults. We compared the estimated BF\% with other ethnicity, and also 

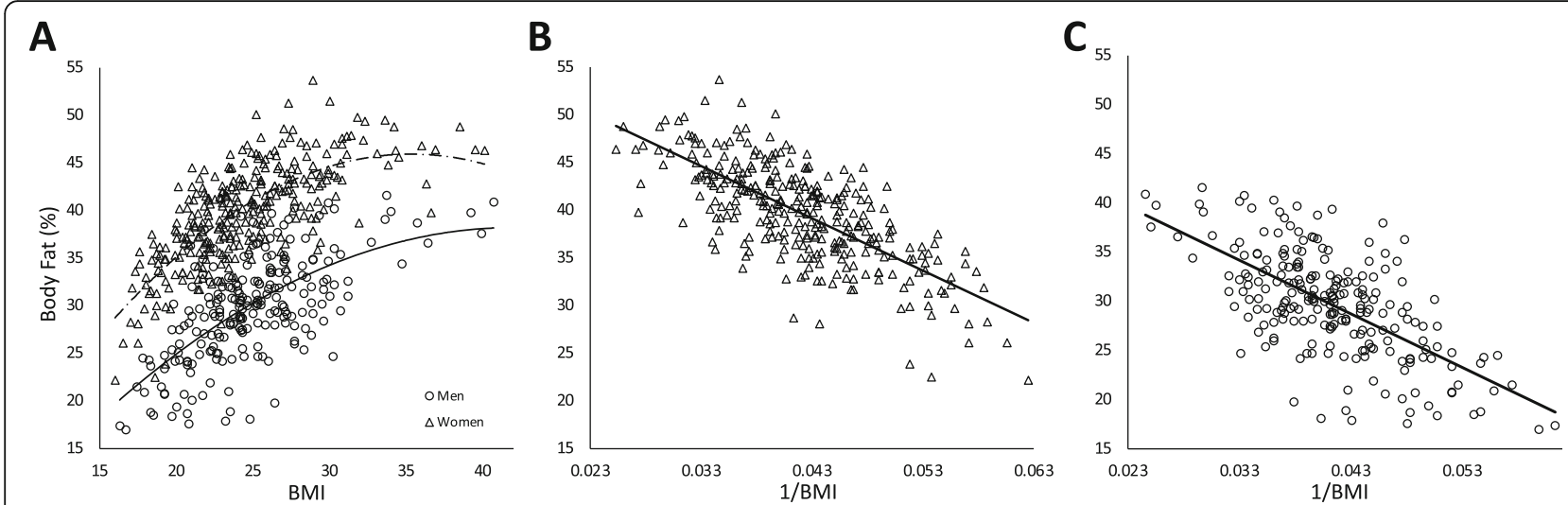

Fig. 1 a Curvilinear relationship between BF\% versus BMI b Linearize relationship between BF\% and 1/BMI in women; $y=-547.66(x)+62.696$; $R^{2}=0.52$ c Linearize relationship between $B F \%$ and $1 / B M I$ in men; $y=-545.14(x)+52.181 ; R^{2}=0.42 ; 0$ : men; $\Delta$ : women

with an earlier study on Singapore population from 20 years ago. Comparing among ethnicities, Singapore Chinese were found to have higher $\mathrm{BF} \%$ compared to Caucasian. This supports the findings from the Singapore study in 2000 [24] and other reports that some Asians population have greater fat mass than Caucasians [14, 32-34]. However, there are other contrasting findings from other Asian populations, such as Vietnamese [31] and Polynesian [35] population that for similar sex, age, and BMI, the BF\% was lower compared to Caucasians - showing the ethnic diversity in percentage body fat in Asia.

Our finding updates the 2000 report [24] in that current cohort of Singaporeans have higher $\mathrm{BF} \%$ at matching BMI, age and sex compared to the cohort from 20 years ago [24]. The changes among Singaporeans may be due to changes in energy balance. Average daily energy intake increased $10 \cdot 3 \%$ from 2004 to 2010 with majority $(59.4 \%)$ of the population exceeding the daily recommended energy intake [36]. This increase in energy intake was not offset by the subsequent $5 \%$ reduction in average daily energy intake between 2010 to 2018 [37].

Table 2 Regression coefficient of the stepwise multiple regression of body fat percentage as dependent variable

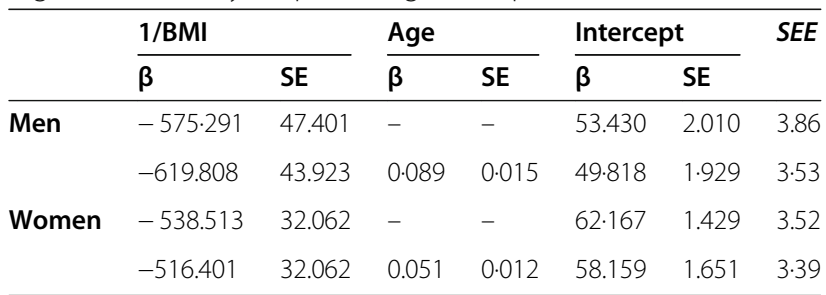

1/BMI 1 divided by Body Mass Index, SE Standard Error, SEE Standard Error of Estimate

\section{Prevalence of overweight and obesity}

The population-adjusted prevalence of overweight and obesity of Singaporeans varied according to the classification used. Prevalence of overweight was 34.4 and $41.8 \%$, obesity was at 12.9 and $26.6 \%$, when using WHO international BMI classification and $\mathrm{MOH}$ classification respectively. When adopting $\mathrm{BF} \%$ criteria, populationadjusted obesity prevalence was substantially higher at $82.0 \%$ (Table 4). The corresponding high populationadjusted prevalence of $\mathrm{WC}>80 \mathrm{~cm}$ for women and $>90$ $\mathrm{cm}$ for men (59.1\% overall, $55.7 \%$ for men and $62.3 \%$ for women in Table 4) suggests that central obesity account for much of this excess body fat in our population. Such substantial higher prevalence with BF\% criteria had also been reported in the Vietnamese [31], and Saudi adults [38]. BMI was found to underestimate prevalence of obesity by about $50 \%$ when compared to $\mathrm{BF} \%[38,39]$. This is in agreement with our results, where prevalence of overweight and obesity was found to be $43.4 \%$ based on BMI and prevalence was $83.2 \%$ based on $\mathrm{BF} \%$ cutoff point. It is well-known that BMI, though highly specific, has low to moderate sensitivity when defining obesity and underestimate prevalence of adult excess body fat, particularly in Asians [31, 40]. While the Chinese and Koreans have proposed population-specific BF\% cut-off $[33,41]$, there is yet no Asian consensus in BF\% cut-off point. Our finding is a step towards such a consensus.

A previous study reported that the lowest all-cause mortality rate in Singapore Chinese was at BMI 18.5$19.9 \mathrm{~kg} / \mathrm{m}^{2}$, with mortality rate significantly increased at BMI $\geq 26.0 \mathrm{~kg} / \mathrm{m}^{2}$ for non-smokers [16], which is lower than the WHO Asian recommendation [13]. Using our derived equation, BMI $18.5-19.9 \mathrm{~kg} / \mathrm{m}^{2}$ equates to $\mathrm{BF} \%$ of $20.9-23.2 \%$ in Chinese men and $32.8-34.8 \%$ in Chinese women aged 50 years. At BMI $26 \mathrm{~kg} / \mathrm{m}^{2}$, BF\% equates to $30.4 \%$ in Chinese men and $40.9 \%$ in Chinese women, which is about $5 \%$ higher than the WHO BF\% 
Table 3 Estimated body fat percentage based on BMI of Singapore Chinese compared with other ethnicities

\begin{tabular}{|c|c|c|c|c|c|c|c|c|c|c|}
\hline & \multicolumn{5}{|l|}{ Men } & \multicolumn{5}{|l|}{ Women } \\
\hline & BMI of 18.5 & BMI of 25 & BMI of 30 & BMI of 35 & BMI of 40 & BMI of 18.5 & BMI of 25 & BMI of 30 & BMI of 35 & BMI of 40 \\
\hline \multicolumn{11}{|l|}{$20-39 y$} \\
\hline Chinese & $19 \cdot 0$ & $27 \cdot 7$ & 31.8 & $34 \cdot 8$ & 37.0 & $31 \cdot 8$ & 39.0 & 42.5 & 44.9 & 46.8 \\
\hline White [29] & $14 \cdot 5$ & 23.9 & 29.8 & $33 \cdot 3$ & $35 \cdot 9$ & $26 \cdot 9$ & 37.0 & $41 \cdot 8$ & $45 \cdot 2$ & $47 \cdot 7$ \\
\hline Japanese [29] & $12 \cdot 8$ & $23 \cdot 2$ & $28 \cdot 1$ & $31 \cdot 6$ & $34 \cdot 3$ & $24 \cdot 6$ & $35 \cdot 2$ & $40 \cdot 2$ & $43 \cdot 8$ & $46 \cdot 5$ \\
\hline Vietnamese [30] & $18 \cdot 3$ & $26 \cdot 5$ & $29 \cdot 8$ & $30 \cdot 6$ & $28 \cdot 8$ & $29 \cdot 2$ & 37.4 & $40 \cdot 7$ & 41.5 & 39.7 \\
\hline \multicolumn{11}{|l|}{$40-59 y$} \\
\hline Chinese & 20.8 & $29 / 5$ & $33 \cdot 6$ & $36 \cdot 6$ & $38 \cdot 8$ & 32.8 & 40.1 & $43 \cdot 5$ & $46 \cdot 0$ & $47 \cdot 8$ \\
\hline White [29] & $15 \cdot 6$ & $25 \cdot 4$ & $30 \cdot 0$ & $33 \cdot 3$ & $35 \cdot 8$ & $27 \cdot 5$ & 37.4 & $42 \cdot 2$ & $45 \cdot 6$ & $48 \cdot 1$ \\
\hline Japanese [29] & $13 \cdot 4$ & $23 \cdot 8$ & $28 \cdot 7$ & $32 \cdot 2$ & 34.9 & 25 & $35 \cdot 5$ & $40 \cdot 2$ & $44 \cdot 1$ & $46 \cdot 8$ \\
\hline Vietnamese [30] & $19 \cdot 1$ & $27 \cdot 2$ & $30 \cdot 5$ & 31.5 & 29.7 & $30 \cdot 1$ & 38.5 & $41 \cdot 8$ & $42 \cdot 4$ & $40 \cdot 6$ \\
\hline \multicolumn{11}{|l|}{$60-79 y$} \\
\hline Chinese & $22 \cdot 7$ & $31 \cdot 3$ & $35 \cdot 3$ & 38.2 & $40 \cdot 4$ & $33 \cdot 8$ & $41 \cdot 1$ & 44.5 & $47 \cdot 0$ & $48 \cdot 8$ \\
\hline White [29] & 19.0 & $28 \cdot 0$ & $32 \cdot 3$ & $35 \cdot 3$ & 37.6 & $31 \cdot 0$ & 39.9 & $44 \cdot 1$ & $47 \cdot 1$ & $49 \cdot 4$ \\
\hline Japanese [29] & 13.9 & $24 \cdot 3$ & $29 \cdot 3$ & $32 \cdot 8$ & $35 \cdot 4$ & $25 \cdot 3$ & $35 \cdot 8$ & $40 \cdot 9$ & $44 \cdot 4$ & $47 \cdot 1$ \\
\hline Vietnamese [30] & $20 \cdot 1$ & $28 \cdot 2$ & $31 \cdot 6$ & $32 \cdot 4$ & $30 \cdot 6$ & 31.0 & $39 \cdot 1$ & $42 \cdot 5$ & $43 \cdot 3$ & $41 \cdot 5$ \\
\hline
\end{tabular}

Estimated body fat percentage calculated centering on the ages of 30,50 , and 70 years

Table 4 Sample and population-age adjusted prevalence of overweight and obesity based on BMI, BF and WC

\begin{tabular}{|c|c|c|c|c|c|c|c|c|c|c|}
\hline & \multicolumn{5}{|c|}{ Sample Estimates } & \multicolumn{5}{|c|}{ Population-Adjusted Estimates } \\
\hline & Overall & 21-59 yrs & $\geq 60$ yrs & $\geq 65$ yrs & $\geq 75$ yrs & Overall & $21-59$ yrs & $\geq 60$ yrs & $\geq 65$ yrs & $\geq 75$ yrs \\
\hline \multicolumn{11}{|l|}{ Total } \\
\hline Overweight & 33.9 & $32 \cdot 3$ & 34.9 & $32 \cdot 7$ & $30 \cdot 1$ & $34 \cdot 4$ & $33 \cdot 4$ & 37.0 & $33 \cdot 4$ & $30 \cdot 0$ \\
\hline Obese & 9.5 & $15 \cdot 9$ & $4 \cdot 6$ & $4 \cdot 8$ & $6 \cdot 6$ & $12 \cdot 9$ & $16 \cdot 2$ & 3.7 & $3 \cdot 7$ & $6 \cdot 5$ \\
\hline $\mathrm{BF} \%$ & $83 \cdot 2$ & $81 \cdot 0$ & $84 \cdot 4$ & $85 \cdot 3$ & $83 \cdot 8$ & $82 \cdot 0$ & $80 \cdot 9$ & $85 \cdot 2$ & $87 \cdot 5$ & $84 \cdot 0$ \\
\hline WC & 63.9 & $55 \cdot 2$ & $70 \cdot 0$ & $70 \cdot 9$ & $70 \cdot 6$ & $59 \cdot 1$ & $55 \cdot 6$ & $68 \cdot 8$ & 69.9 & $70 \cdot 2$ \\
\hline $\mathrm{OW}_{\mathrm{MOH}}$ & $42 \cdot 8$ & $39 \cdot 2$ & $45 \cdot 3$ & $44 \cdot 2$ & $45 \cdot 6$ & $41 \cdot 8$ & $40 \cdot 8$ & $46 \cdot 0$ & $44 \cdot 2$ & $45 \cdot 4$ \\
\hline $\mathrm{OB}_{\mathrm{MOH}}$ & $21 \cdot 8$ & $29 \cdot 3$ & $16 \cdot 0$ & $15 \cdot 5$ & 14.0 & $26 \cdot 6$ & $30 \cdot 3$ & $16 \cdot 3$ & $15 \cdot 4$ & $14 \cdot 0$ \\
\hline \multicolumn{11}{|l|}{ Men } \\
\hline Overweight & 37.6 & 39.6 & $36 \cdot 2$ & $32 \cdot 1$ & $29 \cdot 3$ & $39 \cdot 1$ & $39 \cdot 3$ & $38 \cdot 6$ & $31 \cdot 8$ & 28.5 \\
\hline Obese & $9 \cdot 6$ & $19 \cdot 8$ & 2.9 & 3.7 & 3.4 & 14.9 & 19.4 & $2 \cdot 0$ & 3.0 & 3.4 \\
\hline $\mathrm{BF} \%$ & $81 \cdot 2$ & $79 \cdot 1$ & $82 \cdot 6$ & $85 \cdot 3$ & $81 \cdot 0$ & $80 \cdot 2$ & $79 \cdot 1$ & $83 \cdot 2$ & 88.9 & $80 \cdot 2$ \\
\hline WC & $54 \cdot 1$ & 54.9 & $53 \cdot 6$ & $54 \cdot 1$ & $50 \cdot 0$ & $55 \cdot 7$ & $56 \cdot 7$ & $52 \cdot 9$ & $53 \cdot 6$ & $49 \cdot 1$ \\
\hline $\mathrm{OW}_{\mathrm{MOH}}$ & $45 \cdot 4$ & $41 \cdot 8$ & $47 \cdot 8$ & $45 \cdot 0$ & $43 \cdot 1$ & $44 \cdot 5$ & $42 \cdot 6$ & $50 \cdot 0$ & $45 \cdot 5$ & $41 \cdot 8$ \\
\hline $\mathrm{OB}_{\mathrm{MOH}}$ & $21 \cdot 8$ & 37.4 & $11 \cdot 6$ & $11 \cdot 0$ & 8.6 & $30 \cdot 7$ & 37.4 & $11 \cdot 6$ & $10 \cdot 4$ & $8 \cdot 7$ \\
\hline \multicolumn{11}{|l|}{ Women } \\
\hline Overweight & $31 \cdot 2$ & $27 \cdot 7$ & $34 \cdot 1$ & $33 \cdot 6$ & $31 \cdot 2$ & 29.9 & $27 \cdot 8$ & $35 \cdot 5$ & 34.9 & $31 \cdot 2$ \\
\hline Obese & 9.4 & $13 \cdot 5$ & $6 \cdot 0$ & $5 \cdot 7$ & 9.1 & 11.0 & $13 \cdot 1$ & $5 \cdot 2$ & $4 \cdot 2$ & 8.9 \\
\hline $\mathrm{BF} \%$ & $84 \cdot 7$ & $82 \cdot 3$ & $86 \cdot 8$ & $86 \cdot 4$ & 87.0 & $83 \cdot 8$ & $82 \cdot 6$ & $87 \cdot 1$ & $86 \cdot 2$ & $86 \cdot 9$ \\
\hline WC & $71 \cdot 1$ & $55 \cdot 3$ & $84 \cdot 4$ & $85 \cdot 0$ & 87.0 & $62 \cdot 3$ & $54 \cdot 6$ & $83 \cdot 4$ & $84 \cdot 3$ & $86 \cdot 9$ \\
\hline $\mathrm{OW}_{\mathrm{MOH}}$ & $40 \cdot 9$ & $40 \cdot 9$ & $37 \cdot 6$ & $43 \cdot 7$ & $44 \cdot 3$ & $39 \cdot 3$ & 38.2 & $42 \cdot 3$ & $43 \cdot 0$ & $48 \cdot 2$ \\
\hline $\mathrm{OB}_{\mathrm{MOH}}$ & $21 \cdot 8$ & $24 \cdot 1$ & 19.8 & $19 \cdot 3$ & $18 \cdot 2$ & $22 \cdot 8$ & 23.6 & $20 \cdot 6$ & 19.8 & $18 \cdot 1$ \\
\hline
\end{tabular}

Overweight (BMI $25 \cdot 0-29.9 \mathrm{~kg} / \mathrm{m}^{2}$ ) and obesity (BMI $\geq 30.0 \mathrm{~kg} / \mathrm{m}^{2}$ ) classification based on WHO international classification.; BF\% (body fat percentage) - Men: $25 \%$; Women: 30\%; WC (waist circumference) - Men: $90 \mathrm{~cm}$; Women: $80 \mathrm{~cm} ; \mathrm{OW}_{\mathrm{MOH}}$ (BMl 23.0-27.4 kg/m2) and OB $\mathrm{MOH}\left(\mathrm{BMI}_{2} \geq 27 \cdot 5 \mathrm{~kg} / \mathrm{m}^{2}\right.$ ) classification uses the Singapore MOH Clinical Practice Guidelines BMI classification 
cut-off. Using the criteria of $\mathrm{BF} \% \geq 30.4 \%$ in men and $\geq$ $40.9 \%$ in women, $45 \%$ of men and $44 \%$ of women have increased mortality risk. These estimates are much higher than the prevalence based on BMI $\geq 30 \mathrm{~kg} / \mathrm{m}^{2}$, but much lower than using the WHO BF\% cutoff. Differences in prevalence based on BMI is expected because the relationship between BMI and body fat content varies according to body build and proportion [2]. People with low relative sitting height (i.e. length from the superior midline of the head to the sitting surface) will have a relatively low BMI compared to their BF\% [42], but our Asian population have high relative sitting height [43]. The smaller body frame of Singapore Chinese partially contributed to their having higher $\mathrm{BF} \%$ at the same BMI [43]. Physical inactivity is likely another contributing factor. The 2010 National Health Survey found $39.1 \%$ of Singaporeans did not meet the recommended physical activity guidelines [44]. The increase in energy intake and lack of physical activity could explain the high BF\% in Singaporeans. Such high BF\% in Singaporeans may explain the leading contributions to disease burden by cardiovascular disease and cancer [45]. Our study suggests that WHO international and local Health Ministry BMI classification still underestimated the obesity prevalence in Singapore [24]. Given the high discrepancy between prevalence of obesity using BMI versus $\mathrm{BF} \%$, the prediction equations for $\mathrm{BF} \%$ from $\mathrm{BMI}$ provides a basis and impetus towards establishing healthy body fat ranges in Singapore.

\section{Strength and limitation}

The strengths of this study are its population-based, random selection of participants and hence representativeness and validity of data. The ideal method to determine body composition is the multi-compartment model [30], however such method is inaccessible, expensive and require participants to undergo multiple test. DXA, though may have its limitations, has been used in multiple national population surveys and considered the "gold standard" for measuring body composition parameters $[31,46]$. There are some limitations to this study. While representative proportions of Malays and Indians were recruited via random sampling, their sample sizes of were too small for ethnic comparisons. Hence, oversampling of Malay and Indian ethnic groups would be needed for ethnic comparison and establishment of a $\mathrm{BF} \%$ prediction tool. A thorough investigation into the nutrition intake and physical activity may help understand the large discrepancy between BMI and BF\%. Future research should utilize a long-term prospective study to define the threshold for obesity, based on the relationship between $\mathrm{BF} \%$, all-cause and cause-specific mortality.
In conclusion, our study found a large discrepancy between $\mathrm{BF} \%$ and $\mathrm{BMI}$ measurement in Singaporean adults. The results confirmed that Singaporean adults have higher $\mathrm{BF} \%$ at lower $\mathrm{BMI}$ compared to Caucasians and that $\mathrm{BF} \%$ in our population have also increased over two decades. Further investigation into the body build, nutrition intake, physical activity level among the different ethnic groups may help understand the relationship between BF\% and BMI.

\section{Abbreviations}

BMI: Body mass index; BF\%: Percentage body fat; DXA: Dual energy x-ray absorptiometry; MOH: Ministry of Health; T2DM: Type 2 Diabetes; US: United States of America; UK: United Kingdom; WC: Waist Circumference

\section{Supplementary Information}

The online version contains supplementary material available at https://doi. org/10.1186/s12889-021-11070-7.

Additional file 1 : Supplementary Table. Comparing estimated BF\% at various BMI point of Singaporean Chinese in this study versus the 1998 National Health Survey.

\section{Acknowledgements}

The authors gratefully acknowledge the support of Daniella Ng, Queenie Tan, Dr. Lilian Chye, Sylvia Ngu, Aizuriah Mohamed Ali, Mary Ng, Xing Ying Chua and Shermaine Thein in study logistics and data collection for this study. The authors gratefully acknowledge the strong support of Prof Pang Weng Sun in making this Yishun study possible.

\section{Authors' contributions}

Drafting of the manuscript: KKC, SLW, TPN. Study concept and design: SLW, TPN. Acquisition of data: BWJP, LKL, KAJ, KKC, WTS. Analysis and interpretation of data: KKC, BWJP, SLW, LKL, KAJ, WTS, TPN. Critical revision of the manuscript for important intellectual content: SLW, TPN. All authors have read and approved the manuscript.

Funding

This research was supported as part of a core funding from the Ministry of Health $(\mathrm{MOH})$ of Singapore to GERI (intramural project GERI 1609).

\section{Availability of data and materials}

The data that support the findings of this study are available from the corresponding author SLW, upon reasonable request. The data are not publicly available due to institutional regulations regarding data containing information that could compromise the privacy of research participants.

\section{Declarations}

Ethics approval and consent to participate

Ethics approval was obtained from the National Healthcare Group Domain Specific Review Board (2017/00212). All respondents signed informed consent before their participation in the study.

\section{Consent for publication}

Not applicable.

\section{Competing interests}

Kexun Kenneth Chen, Benedict Wei Jun Pang, Lay Khoon Lau, Khalid Abdul Jabbar, Wei Ting Seah, Tze Pin Ng, and Shiou-Liang Wee declare that they have no conflict of interest.

\section{Author details}

${ }^{1}$ Geriatric Education and Research Institute (GERI), 2 Yishun Central 2, Tower E Level 4 GERI Admin, Singapore 768024, Singapore. ${ }^{2}$ Faculty of Health and Social Sciences, Singapore Institute of Technology, Singapore, Singapore.

${ }^{3}$ Programme of Health Services and System Research, Duke-National 
University of Singapore Graduate Medical School, Singapore, Singapore. ${ }^{4}$ Department of Psychological Medicine, National University of Singapore, Singapore, Singapore.

Received: 3 August 2020 Accepted: 16 May 2021

Published online: 01 June 2021

\section{References}

1. Kyle TK, Dhurandhar EJ, Allison DB. Regarding obesity as a disease: evolving policies and their implications. Endocrinol Metab Clin N Am. 2016;45(3):51120. https://doi.org/10.1016/j.ecl.2016.04.004.

2. World Health Organization. Obesity: preventing and managing the global epidemic: report of a WHO consultation. Geneva: World Health Organisation; 2000.

3. Wang YC, McPherson K, Marsh T, Gortmaker SL, Brown M. Health and economic burden of the projected obesity trends in the USA and the UK. Lancet. 2011;378(9793):815-25. https://doi.org/10.1016/S0140-6736(11 60814-3.

4. World Health Organization. Physical status: the use and interpretation of anthropometry. 1995.

5. World Health Organization. Global Health Observatory (GHO) data Overweight and obesity 2020 [Available from: https://www.who.int/gho/ ncd/risk_factors/overweight_obesity/obesity_adults/en/].

6. Chooi YC, Ding C, Magkos F. The epidemiology of obesity. Metab Clin Exp. 2019;92:6-10. https://doi.org/10.1016/j.metabol.2018.09.005.

7. Ramachandran A, Chamukuttan S, Shetty SA, Arun N, Susairaj P. Obesity in Asia--is it different from rest of the world. Diabetes Metab Res Rev. 2012; 28(Suppl 2):47-51. https://doi.org/10.1002/dmrr.2353.

8. NCD Risk Factor Collaboration (NCD-RisC). Worldwide trends in body-mass index, underweight, overweight, and obesity from 1975 to 2016: a pooled analysis of 2416 population-based measurement studies in 128.9 million children, adolescents, and adults. Lancet. 2017;390(10113):2627-42. https:// doi.org/10.1016/S0140-6736(17)32129-3.

9. Health Promotion Board, Ministry of Health. Obesity HPB-MOH Clinical Practice Guidelines 1/2016. Singapore: Health Promotion Board, Singapore: 2016.

10. Ross R, Neeland IJ, Yamashita S, Shai I, Seidell J, Magni P, et al. Waist circumference as a vital sign in clinical practice: a consensus statement from the IAS and ICCR working group on visceral obesity. Nat Rev Endocrinol. 2020;16(3):177-89. https://doi.org/10.1038/s41574-019-0310-7.

11. Wang J, Thornton JC, Russell M, Burastero S, Heymsfield S, Pierson RD Jr. Asians have lower body mass index (BMI) but higher percent body fat than do whites: comparisons of anthropometric measurements. Am Soc Clin Nutr. 1994;60(1):23-8. https://doi.org/10.1093/ajcn/60.1.23.

12. Deurenberg-Yap M, Chew SK, Lin VFP, Tan BY, Van Staveren WA, Deurenberg P. Relationships between indices of obesity and its comorbidities in multi-ethnic Singapore. Int J Obes. 2001;25(10):1554-62. https://doi.org/10.1038/sj.ijo.0801739.

13. World Health Organization. Appropriate body-mass index for Asian populations and its implications for policy and intervention strategies. Lancet. 2004;363(9403):157-63.

14. Johari SM, Nordin NJ, Sahar MA, Sulaiman AH, Shahar S, Teng NIMF, et al. High body fat percentage among adult women in Malaysia: the role of lifestyle. J Fundam Appl Sci. 2017;9(4S):905-19.

15. Deurenberg P. Universal cut-off BMI points for obesity are not appropriate. Br J Nutr. 2001:85(2):135-6. https://doi.org/10.1079/BJN2000273.

16. Odegaard AO, Pereira MA, Koh WP, Gross MD, Duval S, Yu MC, et al. BMI, allcause and cause-specific mortality in Chinese Singaporean men and women: the Singapore Chinese health study. PLoS One. 2010;5(11):e14000 https://doi.org/10.1371/journal.pone.0014000.

17. De Lorenzo A, Deurenberg P, Pietrantuono M, Di Daniele N, Cervelli V, Andreoli A. How fat is obese? Acta Diabetol. 2003;40(SUPPL. 1):254-7.

18. Deurenberg P, Weststrate JA, Seidell JC. Body mass index as a measure of body fatness: age- and sex-specific prediction formulas. Br J Nutr. 1991;65(2): 105-14. https://doi.org/10.1079/BJN19910073.

19. Deurenberg $P$, Yap M, van Staveren WA. Body mass index and percent body fat: a meta analysis among different ethnic group. Int J Obes. 1998; 22(12):1164-71. https://doi.org/10.1038/sj.ijo.0800741.

20. Ho-Pham LT, Lai TQ, Nguyen ND, Barrett-Connor E, Nguyen TV. Similarity in percent body fat between white and Vietnamese women: implication for a universal definition of obesity. Obesity (Silver Spring). 2010;18(6):1242-6. https://doi.org/10.1038/oby.2010.19.

21. Department of Statistics S. Population trends, 2019. 2019.

22. Lee YS, Biddle S, Chan MF, Cheng A, Cheong M, Chong YS, et al. Health promotion board-ministry of health clinical practice guidelines: obesity. Singap Med J. 2016;57(6):292-300. https://doi.org/10.11622/smedj.2016103.

23. Deurenberg-Yap M, Tan BY, Chew SK, Deurenberg P, van Staveren WA. Manifestation of cardiovascular risk factors at low levels of body mass index and waist-to-hip ratio in Singaporean Chinese. Asia Pac J Clin Nutr. 1999; 8(3):177-83. https://doi.org/10.1046/j.1440-6047.1999.00091.x.

24. Deurenberg-Yap M, Schmidt G, Van Staveren WA, Deurenberg P. The paradox of low body mass index and high body fat percentage among Chinese, Malays and Indians in Singapore. Int J Obes. 2000;24(8):1011-7. https://doi.org/10.1038/sj.ijo.0801353.

25. World Health Organization. World Health Statistics 2020: monitoring health for the SDGs, sustainable developement goals, vol. 2020. Geneva: World Health Organization; 2020.

26. Hogg R, Tanis E, Zimmerman D. Probability and statistical inference. 9th ed. London, United Kingdom: Pearson; 2015:202.

27. Arroyo M, Rocandio AM, Ansotegui L, Herrera H, Salces I, Rebato E. Comparison of predicted body fat percentage from anthropometric methods and from impedance in university students. Br J Nutr. 2004;92(5): 827-32. https://doi.org/10.1079/BJN20041273.

28. Flegal KM. Is an inverted weight-height index a better index of body fatness? Obes Res. 1992;5:93S.

29. Heymsfield SB, Tighe A, Wang ZM. Nutritional assessment by anthropometric and biochemical methods. In: Shils ME, Olson JA, Shike M, editors. Modern nutrition in health and disease. 8th ed. Philadelphia: Lea and Febiger; 1992. p. 812-41.

30. Gallagher D, Heymsfield SB, Heo M, Jebb SA, Murgatroyd PR, Sakamoto Y. Healthy percentage body fat ranges: an approach for developing guidelines based on body mass index. Am J Clin Nutr. 2000;72(3):694-701. https://doi. org/10.1093/ajcn/72.3.694.

31. Ho-Pham LT, Lai TQ, Nguyen MT, Nguyen TV. Relationship between body mass index and percent body fat in Vietnamese: implications for the diagnosis of obesity. PLoS One. 2015;10(5):e0127198. https://doi.org/10.13 71/journal.pone.0127198.

32. Lu YC, Lin YC, Yen AM, Chan WP. Dual-energy X-ray absorptiometryassessed adipose tissues in metabolically unhealthy normal weight Asians. Sci Rep. 2019;9(1):17698. https://doi.org/10.1038/s41598-019-53557-9.

33. Li L, Wang C, Bao Y, Peng L, Gu H, Jia W. Optimal body fat percentage cutoffs for obesity in Chinese adults. Clin Exp Pharmacol Physiol. 2012;39(4): 393-8. https://doi.org/10.1111/j.1440-1681.2012.05684.x.

34. Gurrici S, Hartriyanti Y, Hautvast JG, Deurenberg P. Relationship between body fat and body mass index: differences between Indonesians and Dutch Caucasians. Eur J Clin Nutr. 1998;52(11):779-83. https://doi.org/10.1038/sj. ejcn.1600637.

35. Craig P, Halavatau V, Comino E, Caterson I. Differences in body composition between Tongans and Australians: time to rethink the healthy weight ranges? Int J Obes. 2001;25(12):1806-14. https://doi.org/10.1038/sj.ijo.0801 822.

36. Health Promotion Board Singapore. Report of the National Nutrition Survey 2010. Singapore: Health Promotion Board Singapore; 2010.

37. Health Promotion Board Singapore. National Nutrition Survey 2018 Shows Gradual Improvements in Singaporeans' Dietary Habits: Health Promotion Board Singapore; 2018 [Available from: https://www.hpb.gov.sg/article/na tional-nutrition-survey-2018-shows-gradual-improvements-in-singaporeansdietary-habits].

38. Habib SS. Body mass index and body fat percentage in assessment of obesity prevalence in Saudi adults. Biomed Environ Sci. 2013;26(2):94-9. https://doi.org/10.3967/0895-3988.2013.02.003.

39. Costa-Urrutia P, Vizuet-Gamez A, Ramirez-Alcantara M, Guillen-Gonzalez MA, Medina-Contreras O, Valdes-Moreno M, et al. Obesity measured as percent body fat, relationship with body mass index, and percentile curves for Mexican pediatric population. PLoS One. 2019;14(2):e0212792. https://doi. org/10.1371/journal.pone.0212792.

40. Okorodudu DO, Jumean MF, Montori VM, Romero-Corral A, Somers VK, Erwin PJ, et al. Diagnostic performance of body mass index to identify obesity as defined by body adiposity: a systematic review and metaanalysis. Int J Obes. 2010;34(5):791-9. https://doi.org/10.1038/ijo.2010.5. 
41. Kim CH, Park HS, Park M, Kim H, Kim C. Optimal cutoffs of percentage body fat for predicting obesity-related cardiovascular disease risk factors in Korean adults. Am J Clin Nutr. 2011;94(1):34-9. https://doi.org/10.3945/ajcn.110.001 867.

42. Norgan NG. Population differences in body composition in relation to body mass index. Eur J Clin Nutr. 1994;48:S10-25.

43. Deurenberg P, Deurenberg-Yap M, Wang J, Lin FP, Schmidt G. The impact of body build on the relationship between body mass index and percent body fat. Int J Obes. 1999;23(5):537-42. https://doi.org/10.1038/sj.ijo.0800868.

44. Epidemiology \& Disease Control Division $\mathrm{MoH}$, Singapore. National Health Survey 2010. Singapore: Epidemiology \& Disease Control Division, Ministry of Health; 2010.

45. Epidemiology \& Disease Control Division $\mathrm{MOH}$, Singapore, Institute For Health Metrics And Evaluation. The Burden of Disease in Singapore, 19902017: An overview of the global burden of disease study 2017 results. Washington: IHME; 2019.

46. Kelly TL, Wilson KE, Heymsfield SB. Dual energy X-ray absorptiometry body composition reference values from NHANES. PLOS ONE. 2009;4(9):e7038-e.

\section{Publisher's Note}

Springer Nature remains neutral with regard to jurisdictional claims in published maps and institutional affiliations.

- fast, convenient online submission

- thorough peer review by experienced researchers in your field

- rapid publication on acceptance

- support for research data, including large and complex data types

- gold Open Access which fosters wider collaboration and increased citations

- maximum visibility for your research: over $100 \mathrm{M}$ website views per year

At BMC, research is always in progress. 